\title{
This is JPHE, 3(1), 2021
}

Readers, Authors, Reviewers and Editorial Board Members, on behalf of the Editorial Team of JPHE, I am delighted to share JPHE's fourth issue with you.

This issue is the result of a particularly hectic but also a creative period of time in which the journal has developed significantly. It is also an issue that can no longer hide behind beginner's luck. From that point of view, it is time for me, as Editorin-Chief, to share some of my thoughts on where this journal is now situated and where it is heading.

To start with, JPHE has been, in recent months, in a very productive phase. We have a new online platform (Open Journal System-OJS) and have worked hard to refine our editorial processes. We have a new Editorial Team member, Dr Laura Louise Sarauw; a new Editorial Board (EB) member, Professor Maresi Nerad; and a distinguished Guest Editor, Professor Bruce Macfarlane. We have started a critical dialogue with EB members, discussing new ideas on seminars and an open review system, and we are in the process of preparing our first Special Issue. Most importantly, however, we have a growing number of readers and submitting authors representing an archipelago of research fields and areas of engagement. For us, this is a positive sign of the potential and originality of JPHE, but also confirmation of the need for this kind of journal.

This sketched development corresponds well with our intentions in establishing this journal in 2018. At that time, we identified a gap in research stemming from often over-simplified binaries and sometimes lack of nuances between research, pedagogy, and academic development in higher education. We started JPHE to challenge and to some extent bridge that gap (see Editorial, 1[1], 2019), but also to highlight and critically elaborate on the political and moral dimensions of higher education - hence our spotlight on praxis. This new issue is a good example of how research journals can work to develop new ideas and create bridges across all sorts of gaps and barriers, as well as between different scientific areas. It also gives an example of another intention with this journal: to offer a platform for critical dialogue about worthwhile higher education research. 
This latest JPHE issue thus contains a variety of critical perspectives, ideas on praxis, study objectives, and academic critical debates. In the article by Taylor, concerns are raised about access and equity issues in higher education and, in particular, how academic institutions, policy, and practice are routinely made Anglocentric. The analysis illustrates how alternative practices-so called nonroutine work - brought to the institution by students with diverse language knowledge would challenge understandings of linguistic capital. Also, it addresses implications for linguistic equity and the practicality of polylingual institutional support.

In Beach's critical ethnographic study, the structure of decision-making for exploiting the accumulated labour of teacher educators and their students in Swedish higher education are explored. It is argued that teaching intensive fields are often strongly criticised for the scientific quality of their content, and that this critique needs to be problematised in light of institutional research investment. The level of research investment, according to Beach, tends to be so low that teaching intensive fields have serious difficulty maintaining adequate scientific research connections for programs and career opportunities for research-qualified staff.

Hopwood offers a re-reading of an article published in JPHE 2(1), 'Learning of academics in the time of the Coronavirus pandemic' by Sjølie et al. (2020), exemplifying the kind of critical scholarly debate that JPHE hopes to inspire. Drawing on Stetsenko's transformative activist stance, Hopwood challenges the authors' conservative emphasis on academics' response and adaptation in their account of academics' learning during the pandemic, and suggests that attention instead to academics' agency and contribution (evident in the authors' stories but not explicitly discussed as such) would not only be more in line with the critical and transformative aspects of the theory they employ-the theory of practice architectures - but also the notion of transformative praxis as acting to realise alternative futures.

Fremstad's study departs in questions on the empirical and conceptual basis for discussing what educating students in higher education for social responsibility requires, together with a framework for analysing and planning for this kind of teaching. For example, Fremstad highlights the importance for students to acquire prospects of contributing to change in education systems, their rules, and regulations, and how they need to learn to think creatively and independently, but also engage in critical perspectives. 
The issue also includes two new sections: Interviews and Notes from the Field. You find Shaughnessy's interview with Professor Gerald Cupchik from the University of Toronto in which questions are raised on mentoring practices and contemporary challenges. Professor Cupchik's rich experiences over four decades provide valuable insights into how mentoring practices change and develop over time, and what can become particularly important in that process. The first contribution to Notes from the Field includes descriptive notes by Garrote and Pettersson on the current day-to-day work issues for academic lecturers in their work with online education. We think that the section will provide an important forum for sharing and testing early research findings.

Together the contributions in this issue of JPHE address a variety of highly interesting, important, but also complex issues regarding praxis in higher education today.

Despite the variety of contributions to our issues to date, we recognise a need for a more diverse range of perspectives to broaden and enrich the conversation facilitated by the journal. For example, articles already published in JPHE have largely reflected Nordic, Anglocentric, and/or western perspectives. We are thus committed to opening up the conversation to alternative paths and perspectives in our future work and journal issues. To this end, after the northern summer (from September), we are initiating a series of research seminars in which we will explore the concept of praxis from multiple perspectives. Initially, these seminars will include the journal's Editorial Team, EB members, colleagues, and close networks. However, our intention is to also move beyond our own home grounds. We would welcome ideas on how to do this.

Another step in a quest for a more open conversation is the introduction of annual special issues, and our inaugural special issue will provide a fitting start to the series. Entitled 'From "intercultural-washing" to meaningful intercultural education: Revisiting higher education practice', and edited by Mélodine Sommier, Anssi Roiha, and Malgorzata Lahti, the issue both explores and constitutes a space for critical dialogue about transformative intercultural education in higher education. We look forward to the publication in the coming months of this highly relevant and thought-provoking set of contributions to the journal.

Inviting guest editors is another way of ensuring that we do not become too complacent or settled in our work and thinking. Our current Guest Editor, Bruce Macfarlane is very supportive in that respect. Bruce's critical and curious mind keeps us continuously busy. Thank you so much for your engagement! That also 
goes for our newest Senior Editor, Laura Louise Sarauw. We really appreciate that you find the time and energy to engage in our teamwork! We also have plans to broaden the team further to include team members with a background and experiences not yet represented in the team.

Finally, I think I dare to say that we, as a team, are in the very nexus of where we would like to be. Things are not perfect, but that is not the goal either. We are a journal team debating and investigating praxis, which means that we are part of a continuous and reflexive movement, of stable, creative, and new practices to find out what praxis can, could, may, or should mean and be. We are also still ironing out issues with our new platform, and we are continually seeking sources of funding to support the administrative work behind the journal. However, we have the courage, curiosity, capacity, and will to meet these and other challenges. This is why we can and will continue the work on praxis in higher education.

Thank you for the hard work and fantastic engagement of the Editorial Team, the support of an engaged and wise Editorial Board, the sharp scholarly work of our contributing authors, and the careful, generous work of our reviewers. You make this worthwhile.

Petra Angervall

Editor-in Chief

Journal of Praxis in Higher Education

\section{References}

Sjølie, E., Francisco, S., Mahon, K., Kaukko, M., Kemmis, S. (2020). Learning of academics in the time of the coronavirus pandemic. Journal of Praxis in Higher Education, 2(1), 85-107. https://doi.org/10.47989/kpdc61. 